\title{
Hypothyroidism and unusual rickets in a very preterm infant
}

\author{
P. Macmahon, M. Blair and I. Kovar \\ Department of Paediatrics, Charing Cross Hospital, Fulham Palace Road, London W6 8RF, UK.
}

\begin{abstract}
Summary: Two separate episodes of rickets developed in a female infant of 25 weeks gestation and birthweight $690 \mathrm{~g}$, who had congenital hypothyroidism and required parenteral nutrition for more than 100 days. We speculate that there is a relationship between metabolic bone disease of prematurity and the preterm infant's thyroid status.
\end{abstract}

\section{Introduction}

Severe metabolic bone disease, or osteopenia, is common in infants under $1000 \mathrm{~g}$ at birth, with a reported incidence in excess of $50 \%,{ }^{1}$ whereas congenital hypothyroidism occurs in the order of 1 in 4000 of all live births. A retarded bone age and short stature are typical features of hypothyroidism, while longitudinal growth is affected by rickets. ${ }^{2}$ The aetiology of metabolic bone disease is multifactorial; ${ }^{3}$ infants with congenital hypothyroidism are known to have altered calcium and vitamin D metabolism. ${ }^{4}$ It is not known whether there may be an interaction between thyroid hormones and bone mineralization in these infants. It is possible that the development changes in thyroid function ${ }^{5}$ seen during the first few weeks of postnatal life may influence the aetiology and natural history of metabolic bone disease of prematurity.

We report on a low birthweight very preterm infant with congenital hypothyroidism who developed a severe and unusual form of rickets of prematurity. The hypothyroidism or its treatment may have contributed to the rickets by affecting growth at a time when mineral substrate and vitamin $\mathrm{D}$ levels were marginal.

\section{Case report}

The infant was the first of twin girls born at 25 weeks gestation and weighing $690 \mathrm{~g}$. The second twin died on day 2 despite intensive support. Both twins had large goitres at birth. In the first 24 hours the plasma thyroxine $\left(\mathrm{T}_{4}\right)$ concentrations in both babies were low $(<25 \mathrm{nmol} / \mathrm{l})$, while the plasma thyroid stimulating hormone (TSH) levels were $70 \mathrm{mU} / 1$ in twin 1 , and $54 \mathrm{mU} / 1$ in twin 2 . The mother was clinically and

Correspondence: I.Z. Kovar, M.R.C.P. (UK), F.R.C.P. (Canada), D.Obst., R.C.O.G.

Accepted: 7 December 1988 biochemically euthyroid and had no plasma antithyroid antibodies.

Twin 1 required artificial ventilation for a total of $98 \dot{\omega}$ days because of hyaline membrane disease and lung $\vec{N}$ immaturity complicated by bronchopulmonary dysp-응 lasia. A patent ductus arteriosus was surgically ligatedon day 30 after failed medical closure with indo-? methacin.

The infant was fed by total intravenous alimenta- $\overrightarrow{0}$ tion for over 3 months as enteral feeding was neto tolerated. Thyroid hormone replacement with i travenous tri-iodothyronine $\left(\mathrm{T}_{3}\right)$ (Glaxo Laboratorieg, Greenford, UK) was commenced on day 16 at ans initial dose of $4.5 \mu \mathrm{g} / \mathrm{day}$, and this was subsequentlyo titrated against regular TSH and $\mathrm{T}_{3}$ measurements. $\frac{\mathscr{Q}}{\mathbb{Q}}$ The biochemical and clinical parameters are illustated $\varrho$ in Figure 1.

The goitre was no longer clinically apparent after 3 day 30 except for a brief period later when the plasma TSH level increased above $25 \mathrm{mU} / 1$. Enteral feeding? was tolerated only by day 104 and supplementary을 intravenous feeding progressively discontinued. Oral L-thyroxine was commenced on day 122 and normalo thyroid function (total $\mathrm{T}_{4} 124 \mathrm{nmol} / \mathrm{l}$ ) was reestablished after a further two months.

Metabolic bone disease was initially suspected because of an increased plasma alkaline phosphatase activity; rickets was confirmed radiologically on day $\rightarrow$ 45 (Figure 1a). The plasma 25-hydroxycholecalciferol at this stage was normal $(23.2 \mathrm{ng} / \mathrm{ml})$, plasma phos- No phate was low $(0.5 \mathrm{mmol} / \mathrm{l})$, and plasma copper was normal $(15 \mathrm{mmol} / \mathrm{l}$, reference range $10-20 \mathrm{mmol} / \mathrm{l})$.

Subsequent management included increasing the $\mathrm{N}$ mineral substrate intake in the parenteral nutrition solution and prescribing 1-alpha-hydroxycholecal-o ciferol (Alfacalcidol, Leo Laboratories, Bucks, UK). Calcium and phosphorus mineral substrate was pres-? cribed according to a computer based neonatal int $-\frac{T}{T}$ ravenous feeding protocol. The protocol delivered up $\frac{\mathrm{D}}{\mathrm{D}}$

(C) The Fellowship of Postgraduate Medicine, $1989 \stackrel{\stackrel{\Omega}{\mathbb{Q}}}{\Omega}$ 


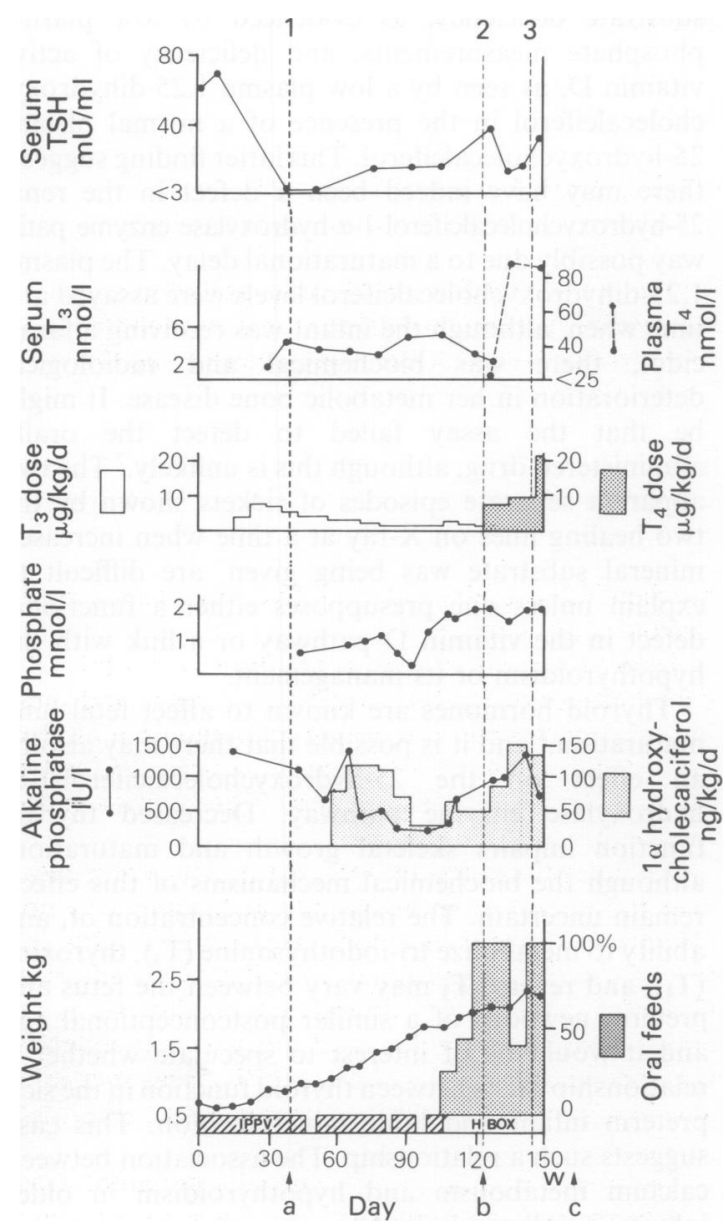

Figure 1 Thyroid function and metabolic bone disease in relation to age. At (1) rickets diagnosed, at (2) evidence of further radiological progression, at (3) X-ray showing two healing lines (see Figure 2). Feeding is shown as percentage of intake.

\begin{tabular}{lccc}
\hline Time (day) & $\begin{array}{c}25 \mathrm{OH} \mathrm{CC} \\
(\mathrm{ng} / \mathrm{ml})\end{array}$ & $\begin{array}{c}1,25 \mathrm{OH}_{2} \mathrm{CC} \\
(\mathrm{pg} / \mathrm{ml})\end{array}$ & $\begin{array}{c}24,25 \mathrm{OH}_{2} \mathrm{CC} \\
(\mathrm{ng} / \mathrm{ml})\end{array}$ \\
\hline a (45) & 23.2 & N/A & N/A \\
b (130) & 26.5 & 3.1 & 1.4 \\
c (180) & 27.6 & 60.6 & 3.7 \\
$\begin{array}{l}\text { Paediatric } \\
\text { ref range }\end{array}$ & $8-45$ & $19-70$ & $1-3$ \\
\hline
\end{tabular}

Vitamin $\mathrm{D}$ concentrations $(\mathrm{CC}=$ cholecalciferol) at times a, b, c. N/A = not applicable. to $1.0 \mathrm{mmol} / \mathrm{kg} /$ day of calcium and $0.7 \mathrm{mmol} / \mathrm{kg} /$ day of phosphorus, based on the infants daily plasma calcium and inorganic phosphate levels. This was modified from day 65 to permit increased calcium (up to $1.5 \mathrm{mmol} / \mathrm{kg} /$ day) and phosphorus (up to $1.0 \mathrm{mmol} /$ $\mathrm{kg} /$ day) to be prescribed. A low birth weight formula (Prematalac, Cow \& Gate, Trowbridge, Wilts, UK) with an equal calcium and phosphorus content of $1.7 \mathrm{mmol} / \mathrm{dl}$ was introduced on day 100 . Alfacalcidol was given orally for several days until an intravenous preparation was made available; the agent was then given intravenously from day 65 to day 122 , and then again orally until 6 months. The dose was titrated against the infant's plasma alkaline phosphatase activity. The plasma alkaline phosphatase activity and inorganic phosphate levels are shown in Figure 1. The plasma calcium concentration remained within the reference range $(2.00-2.60 \mathrm{mmol} / \mathrm{l})$ throughout the clinical course.

There was a second increase in plasma alkaline phosphatase activity associated with decreased alfacalcidol dosage and X-ray evidence of rickets progression (Figure 1.2) and by day 145 (Figure 1.3) there was evidence on X-ray of a second rickets healing line suggestive of a separate episode of significant demineralization (Figure 2). From days 80-150 there was a $3.5 \mathrm{~cm}$ increase in body length.

Respiratory infection together with severe bronchopulmonary dysplasia and cor pulmonale complicated the subsequent clinical course. At one year of age the infant was still oxygen dependent, weighed only $4 \mathrm{~kg}$, and had a bone age equivalent to 6 months. She died at 13.5 months of an unresponsive arrhythmia during an intercurrent infection.

The permitted limited post-mortem examination did not assist in the understanding of her complex disease state. Histological examination of the thyroid of the twin who died early, showed diffuse hyperplasia consistent with a dyshormonogenetic goitre; no enzyme determinations were done.

\section{Methods}

Vitamin D metabolites were assayed in duplicate by competitive protein binding after high pressure liquid gas chromatography separation. Calcium and phosphorus were measured on an American Monitor Parallel analyser using approved methods.

Plasma $T_{4}$ and $T_{3}$ were both assayed by an in-house double antibody radioimmunoassay technique with an adult $\mathrm{T}_{3}$ reference range of $1.4-3.0 \mathrm{nmol} / 1$ with a $\mathrm{CV}$ of $10.6 \%$ at a level of $1.2 \mathrm{nmol} / 1$. The adult plasma total $\mathrm{T}_{4}$ reference range was $60-160 \mathrm{nmol} / 1$ with a CV of $4.4 \%$ at a level of $93 \mathrm{nmol} / \mathrm{l}$. TSH was measured by an in-house immunoradiometric assay with an adult reference range of $0.5-2.9 \mathrm{mU} / 1$ and $\mathrm{a} \mathrm{CV}$ of $6.8 \%$ at a level of $1.3 \mathrm{mU} / 1$. 


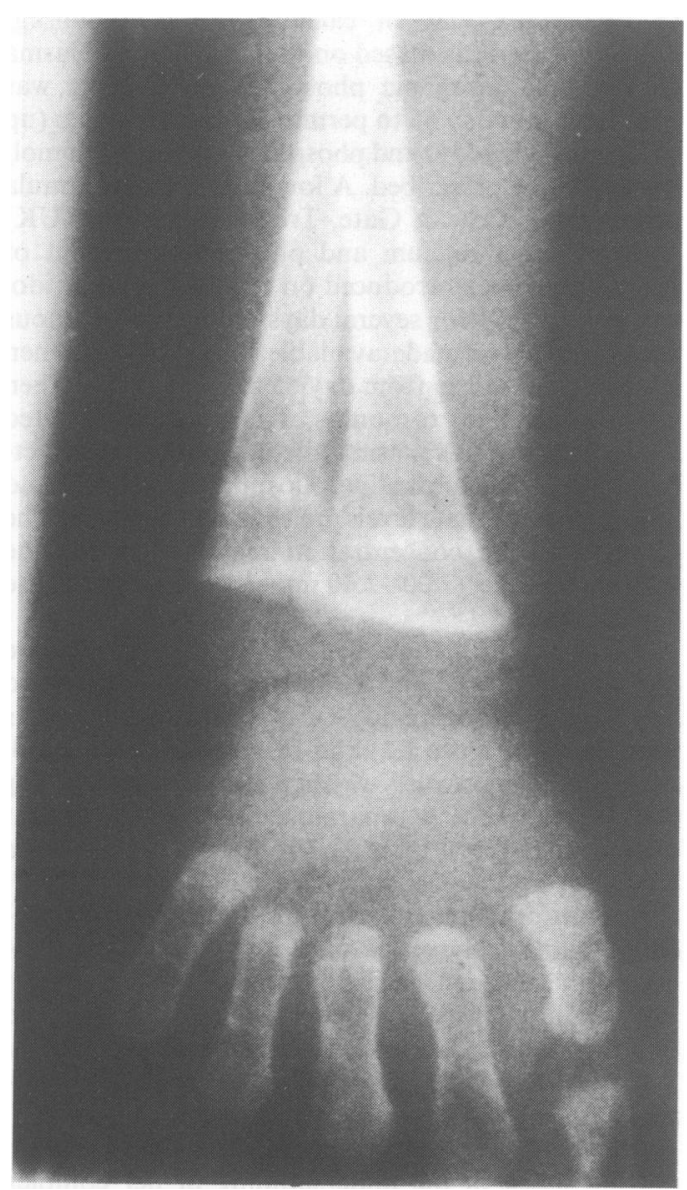

Figure 2 X-ray showing rickets and two healing lines.

\section{Discussion}

We did not set out to study this child in detail, but rather considered this report in retrospect; consequently we recognize that there are gaps in detail. We believe, however, that the case raises several issues which merit consideration, including the need to have adequate guidelines to manage hypothyroidism in the very preterm infant who is ventilator dependent, and the potential relationship between thyroid function and the metabolic bone disease often seen in these infants.

Mineral substrate deficiency is thought to be the major aetiological factor in metabolic bone disease of prematurity. Recent studies have suggested that the preterm infant can adequately hydroxylate 25hydroxycholecalciferol; enzyme immaturity of the vitamin D pathway may, however, be a factor in some infants. ${ }^{3}$ This infant is likely to have had both mineral substrate deficiency, as evidenced by low plasma phosphate measurements, and deficiency of active vitamin $D$, as seen by a low plasma 1,25-dihydroxycholecalciferol in the presence of a normal plasma 25-hydroxycholecalciferol. This latter finding suggests there may have indeed been a defect in the renal 25-hydroxycholecalciferol-1- $\alpha$-hydroxylase enzyme pathway possibly due to a maturational delay. The plasma 1,25-dihydroxycholecalciferol levels were assayed at a time when, although the infant was receiving alfacalcidol, there was biochemical and radiological deterioration in her metabolic bone disease. It might be that the assay failed to detect the orally administered drug, although this is unlikely. ${ }^{7}$ The two apparent separate episodes of rickets shown by the two healing lines on X-ray at a time when increased mineral substrate was being given, are difficult to explain unless one presupposes either a functional defect in the vitamin D pathway or a link with the hypothyroidism or its management.

Thyroid hormones are known to affect fetal lung maturation, ${ }^{8}$ and it is possible that there may also be an effect on the 25-hydroxycholecalciferol-1- $\alpha$ hydroxylase enzyme pathway. Decreased thyroid function impairs skeletal growth and maturation although the biochemical mechanisms of this effect, remain uncertain. The relative concentration of, and ability to metabolize tri-iodothyronine $\left(T_{3}\right)$, thyroxine $\left(T_{4}\right)$, and reverse $T_{3}$ may vary between the fetus and preterm newborn of a similar postconceptional age and it would be of interest to speculate whether a relationship exists between thyroid function in the sick preterm infant and bone mineralization. This case suggests such a relationship. The association between calcium metabolism and hypothyroidism in older infants is well recognized. ${ }^{4}$

The management of congenital hypothyroidism in bigger babies is documented elsewhere, ${ }^{10}$ but there is little published information on ways of deciding on, and monitoring optimum thyroid replacement in the extremely low birthweight infant. The conventional clinical signs such as heart rate were unavailable to us in deciding thyroid replacement in a ventilatordependent infant. Based on TSH measurements alone it is likely that the hypothyroidism in this case was undertreated; the goitre, however, disappeared and plasma $T_{3}$ measurement remained within, or above, the normal range. What is uncertain is whether circulating $T_{3}$ can adequately suppress TSH in sick preterm infants. These babies are biochemically hypothyroxinaemic ${ }^{11}$ with obtunded thyroid control which may not mature until after 30 weeks postconceptional age. ${ }^{11,12}$ The effect on plasma thyroid measurements by repeated blood transfusions and other treatments is unknown. It would seem reasonable to monitor thyroid function in these 
infants by measurement of TSH and either plasma $T_{3}$ or $T_{4}$, depending on the replacement therapy used.

It is possible that either this child's basic hypothyroidism, or the management with $\mathrm{T}_{3}$, and later $T_{4}$, contributed to the course of the clinical metabolic bone disease and its healing. Final healing occurred late in the clinical course; oral thyroxine may have acted as a stimulus to bony growth at a time when both mineral substrate and active vitamin $D$ availability were increased providing more optimum conditions

\section{References}

1. Brooke, O.G. \& Lucas, A. Metabolic bone disease in the preterm infant. Arch Dis Child 1985, 60: 682-685.

2. James, J.A., Mayne, P.D., Barnes, I.C. \& Kovar, I.Z. Growth velocity and plasma alkaline phosphatase activity in the preterm infant. Early Hum Dev 1985, 11: 27-32.

3. Anon (Editorial). Metabolic bone disease of prematurity. Lancet 1987, i: 20.

4. Tau, C., Garabedian, M., Farriaux, J.P., Czernichow, P., Ponaredi, R. \& Balsan, S. Hypercalcaemia in infants with congenital hypothyroidism and its relation to vitamin D and thyroid hormonẹs. $J$ Pediatr 1986, 109: 808-814.

5. Klein, A.H., Foley, B., Kenny, F.M. \& Fisher, D.A. Thyroid hormone and TSH responses to parturition in premature infants with and without the respiratory distress syndrome. Pediatrics 1979, 63: 380-385.

6. Mawer, E.B., Stanbury, S.W., Robinson, M.J., James, J. \& Close, C. Vitamin D nutrition and vitamin D metabolism in the premature human neonate. Clin Endocrinol 1986, 25: 641-649.

7. Kovar, I., Mayne, P., James, J. \& Barnes, I. Oral administration of active vitamin D metabolites to low birthweight infants. Arch Dis Child 1986, 61: 795-797. for rachitic healing. We would speculate that changes in thyroid function in the preterm infant may affect bone growth and mineralization adversely; the importance, if any, of thyroid hormones in promoting maturation of the 25-hydroxycholecalciferol-1- $\alpha$ hydroxylase enzyme is unknown.

\section{Acknowledgement}

We thank Mrs S. Chalkely for technical support.

8. Wu, B., Kikkawa, Y., Orzalesi, O.M. et al. The effect of thyroxine on the maturation of fetal rabbit lungs. Biol Neonate 1973, 22: 161-168.

9. Salmon, T.N. The effect on the growth rate of thyroparathyroidectomy in newborn rats of the subsequent administration of thyroid, parathyroid and anterior hypophysis. Endocrinology 1938, 23: 446-457.

10. Frost, G.J. \& Parkin, J.M. Management and patients with congenital hypothyroidism. Br Med J 1985, 290: 1485-1489.

11. Mercado, M., Yu, V.Y.H., Francis, I. et al. Thyroid function in very preterm infants. Early Hum Dev 1988, 16: $131-141$.

12. Fisher, D.A. \& Klein, A.H. The ontogenesis of thyroid function and its relationship to neonatal thermogenesis. In: Tulchinsky, D. \& Ryan, K. (eds) Maternal-Fetal Endocrinology. W.B. Saunders, Philadelphia, 1980, pp. $281-297$. 